\title{
Coronary artery bypass grafting is superior to first-generation drug-eluting stents for unprotected left main coronary artery disease: An updated meta-analysis of 4 randomized, controlled trials
}

\author{
Umberto Benedetto, MD, PhD, ${ }^{a}$ Colin Ng, MBBS, ${ }^{a}$ Robert Smith, MD, ${ }^{b}$ and \\ Shahzad G. Raja, MRCS, FRCS(C-Th) ${ }^{\mathrm{a}}$; on behalf of the Cardiac Outcomes Meta-Analysis (COMET) \\ Group, London, United Kingdom
}

\begin{abstract}
The optimal treatment approach for patients with unprotected left main coronary artery (ULMCA) disease still remains unclear. ${ }^{1}$ In recent years, as a result of the advent of first-generation drug-eluting stents (DESs), restenosis rates have decreased relative to conventional bare metal stents, and the range of applications of percutaneous coronary intervention for ULMCA disease has been expanded. ${ }^{1}$ Several randomized, controlled trials (RCTs) comparing coronary artery bypass grafting $(\mathrm{CABG})$ with stenting $^{2-5}$ have recently been published, but the results are inconclusive. We aimed to get insights into the treatment of ULMCA disease by conducting an updated meta-analysis and metaregression of the recent RCTs.
\end{abstract}

\section{MATERIALS AND METHODS}

MEDLINE (PubMed) was searched for RCTs that compared outcomes of stenting with DES versus those of CABG in the treatment of ULMCA disease. For each study, data regarding all-cause mortality and the incidences of myocardial infarction, stroke, repeat revascularization, and the composite end point of major adverse cardiac and cerebrovascular events (MACCEs) were used to generate odds ratios (ORs) for stenting relative to $\mathrm{CABG}$ (with $<1$ favoring stenting and $>1$ favoring $\mathrm{CABG}$ ). A pooled summary effect estimate was calculated by means of the Mantel-Haenszel method. Betweenstudy heterogeneity was analyzed by means of the $I^{2}$ index. A random effects model was used for $I^{2}$ values of at least $50 \%$. Subgroup analysis was used to investigate the effects of follow-up duration and SYNTAX (SYNergy between PCI with TAXUS and Cardiac Surgery) score on clinical outcomes.

\section{RESULTS}

A total of $4 \mathrm{RCTs}^{2-5}$ were identified (Table 1) that enrolled a total of 1611 individuals randomly assigned to undergo CABG $(\mathrm{n}=802)$ or stenting $(\mathrm{n}=809)$. In 3 studies, ${ }^{2-4}$ first-generation DESs only (sirolimus- or paclitaxel-eluting stents) were used. In 1 study, ${ }^{5}$ both bare metal stents and DESs were used. Follow-up ranged from 1 to 5 years. No RCTs comparing second-generation DESs with CABG

\footnotetext{
From the Departments of Cardiac Surgery ${ }^{\mathrm{a}}$ and Cardiology, ${ }^{\mathrm{b}}$ Harefield Hospital, London, United Kingdom.

Disclosures: Authors have nothing to disclose with regard to commercial support.

Received for publication June 19, 2014; revisions received July 20, 2014; accepted for publication Aug 17, 2014; available ahead of print Sept 12, 2014.

Address for reprints: Umberto Benedetto, MD, PhD, Cardiothoracic Department, Harefield Hospital, London, UB9 6JH, United Kingdom (E-mail: umberto. benedetto@hotmail.com).

J Thorac Cardiovasc Surg 2014;148:2430-2

$0022-5223 / \$ 36.00$

Copyright (c) 2014 by The American Association for Thoracic Surgery

http://dx.doi.org/10.1016/j.jtcvs.2014.08.028
}

were found. Two studies, the SYNTAX trial' ${ }^{2}$ and the PRECOMBAT (PREmier of Randomized COMparison of Bypass Surgery Versus AngioplasTy Using Sirolimus-Eluting Stent in Patients With Left Main Coronary Artery Disease) trial, ${ }^{4}$ reported on the MACCE rates in high $(n=464)$ and low to intermediate $(\mathrm{n}=795)$ SYNTAX score groups, although different cutoffs were used (33 and 30, respectively).

Pooled estimates showed that stenting was comparable to CABG in terms of all-cause death (OR, 0.79; 95\% CI, $\left.0.54-1.15 ; P=.21 ; I^{2}=0 \%\right)$ and myocardial infarction (OR, 1.49; 95\% CI, 0.88-2.50; $P=.14 ; I^{2}=0 \%$ ). Stenting was associated with a reduced risk of stroke (OR, 0.33; $\left.95 \%, \mathrm{CI}, 0.14-0.77 ; P=.01 ; I^{2}=0 \%\right)$ but an increased risk of repeat revascularization (OR 2.21; 95\% CI, 1.62 $\left.3.00 ; P<.00001 ; I^{2}=0 \%\right)$. Overall, stenting was significantly associated with a higher rate of MACCEs (OR, $1.39 ; 95 \%$ CI, 1.09-1.77; $P=.009 ; I^{2}=0 \%$; Figure 1$)$. Subgroup analysis for MACCE rate according to followup duration showed that the stenting was significantly inferior to CABG in studies with a follow-up longer than 1 year $^{2-4}$ (OR, 1.41; 95\% CI, 1.08-1.85; $P=.01 ; I^{2}=0 \%$ ), whereas this disadvantage was less evident in studies ${ }^{3-5}$ with a follow-up within 1 year (OR, 1.30; 95\% CI, 0.74$2.26 ; P=.36 ; I^{2}=0 \%$ ).

Subgroup analysis of the MACCE rate according to the SYNTAX score (Figure 1) suggested that the inferiority of stenting relative to CABG was particularly evident for patients with high SYNTAX scores (OR, 1.93; 95\% CI, $1.26-2.96 ; P=.002 ; I^{2}=0 \%$ ), whereas the inferiority of stenting was less consistent in patients with low to intermediate SYNTAX scores (OR, 1.34; 95\% CI, $0.67-2.68 ; P=.4 ; I^{2}=61 \%$ ).

Pooled estimates did not significantly change when studies including DESs only ${ }^{2-4}$ were included $(P=.59$, $P=.07, P=.02, P<.00001$, and $P=.01$ for all-cause death, myocardial infarction, stroke, repeat revascularization, and MACCEs, respectively).

\section{DISCUSSION}

A recently published meta-analysis ${ }^{1}$ pooling data from observational studies and RCTs concluded that there was no significant difference in combined MACCEs between DES and CABG, thus supporting the conclusion that DES is a safe and durable alternative to CABG. Results from 
TABLE 1. Study overview

\begin{tabular}{|c|c|c|c|c|c|c|c|c|}
\hline Study & Year & Size & Male & Mean age $(y)$ & Diabetes & Mean SYNTAX score & Type of stent & $\mathbf{F U}$ \\
\hline $\begin{array}{l}\text { Morice et al, }{ }^{2} \\
\text { SYNTAX trial }\end{array}$ & 2014 & 705 & $\begin{array}{l}\text { DES, } 72 \% ; \\
\quad \text { CABG, } 76 \%\end{array}$ & $\begin{array}{l}\text { DES, } 65 ; \\
\quad \text { CABG, } 66\end{array}$ & $\begin{array}{l}\text { DES, } 24 \% ; \\
\quad \text { CABG, } 26 \%\end{array}$ & $\begin{array}{l}\text { DES, 28.1; } \\
\quad \text { CABG, } 26.7\end{array}$ & PES & $5 y$ \\
\hline Boudriot et $\mathrm{al}^{3}$ & 2011 & 201 & $\begin{array}{l}\text { DES, } 72 \% ; \\
\quad \text { CABG, } 77 \%\end{array}$ & $\begin{array}{l}\text { DES, 66; } \\
\text { CABG, } 69\end{array}$ & $\begin{array}{l}\text { DES, } 40 \% \\
\quad \text { CABG, } 33 \%\end{array}$ & $\begin{array}{l}\text { DES, 24.0; } \\
\quad \text { CABG, } 23.0\end{array}$ & SES & $1 \mathrm{y}$ \\
\hline $\begin{array}{l}\text { Park et al, } \\
\quad \text { PRECOMBAT }\end{array}$ & 2011 & 600 & $\begin{array}{l}\text { DES, } 76 \% ; \\
\quad \text { CABG, } 77 \%\end{array}$ & $\begin{array}{l}\text { DES, } 62 ; \\
\quad \text { CABG, } 63\end{array}$ & $\begin{array}{l}\text { DES, } 34 \% \\
\text { CABG, } 30 \%\end{array}$ & $\begin{array}{l}\text { DES, 24.4; } \\
\quad \text { CABG, } 25.8\end{array}$ & SES & $2 y$ \\
\hline $\begin{array}{l}\text { Buszman et al, } \\
\text { LE MANS study }\end{array}$ & 2008 & 105 & $\begin{array}{l}\text { Stent, } 60 \% ; \\
\quad \text { CABG, } 73 \%\end{array}$ & $\begin{array}{l}\text { Stent, 60; } \\
\quad \text { CABG, } 61\end{array}$ & $\begin{array}{l}\text { Stent, } 19 \% \\
\quad \text { CABG, } 17 \%\end{array}$ & $\begin{array}{l}\text { Stent, 25.2; } \\
\quad \text { CABG, } 24.7\end{array}$ & $\begin{array}{l}\text { DES, } * 35 \% \\
\text { BMS, } 65 \%\end{array}$ & $1 \mathrm{y}$ \\
\hline
\end{tabular}

$F U$, Follow-up; $D E S$, drug-eluting stent; $C A B G$, coronary artery bypass grafting; $P E S$, paclitaxel-eluting stent; $S E S$, sirolimus-eluting stent; $B M S$, bare metal stent. $*$ Type not specified.

observational studies are likely to be distorted by patients selection bias, however, and meta-analyses of RCTs remain the standard criterion to summarize evidence. In addition, no previous meta-analysis has included the recently published 5-year follow-up SYNTAX trial results. ${ }^{2}$
According to our findings, CABG appears to be superior to first-generation DESs in the treatment of ULMCA disease by significantly reducing the overall incidence of MACCEs, mainly driven by reduction in further revascularization. The superiority of CABG seems to be

Overall analysis

\begin{tabular}{|c|c|c|c|c|c|c|c|c|c|}
\hline \multirow[b]{2}{*}{ Study } & \multicolumn{2}{|c|}{$\mathrm{PCl}$} & \multicolumn{2}{|c|}{ CABG } & \multicolumn{2}{|r|}{ Odds Ratio } & \multirow{2}{*}{\multicolumn{3}{|c|}{$\begin{array}{c}\text { Odds Ratio } \\
\text { M-H, Fixed, } 95 \% \mathrm{Cl}\end{array}$}} \\
\hline & Events & Total & Events & Total & Weight & M-H, Fixed, 95\% Cl & & & \\
\hline Boudriot & 19 & 100 & 16 & 101 & $11.8 \%$ & $1.25[0.60,2.59]$ & & & \\
\hline LE MANS & 16 & 52 & 13 & 53 & $8.2 \%$ & $1.37[0.58,3.23]$ & & & \\
\hline PRECOMBAT & 36 & 300 & 24 & 300 & $19.3 \%$ & $1.57[0.91,2.70]$ & & & \\
\hline SYNTAX LM Subgroup & 130 & 357 & 103 & 348 & $60.7 \%$ & $1.36[0.99,1.87]$ & & & \\
\hline Total $(95 \% \mathrm{Cl})$ & & 809 & & 802 & $100.0 \%$ & $1.39[1.09,1.77]$ & & & \\
\hline Total events & 201 & & 156 & & & & & & \\
\hline \multicolumn{7}{|c|}{$\begin{array}{l}\text { Heterogeneity: } C^{2}=0.29, d f=3(P=0.96) ; I^{2}=0 \% \\
\text { Test for overall effect: } Z=2.63(P=0.009)\end{array}$} & $\begin{array}{c}1 \\
0.5 \\
\text { Favours }\end{array}$ & $\begin{array}{l}0.7 \\
\text { stenting }\end{array}$ & $\begin{array}{cc}1 & 1 \\
1.5 & 2 \\
\text { Favours } \mathrm{CABG}\end{array}$ \\
\hline
\end{tabular}

Subgroup: high SYNTAX score ${ }^{*}$

\begin{tabular}{|c|c|c|c|c|c|c|c|c|c|c|}
\hline \multirow[b]{2}{*}{ Study } & \multicolumn{2}{|c|}{$\mathrm{PCl}$} & \multicolumn{2}{|c|}{ CABG } & \multicolumn{2}{|r|}{ Odds Ratio } & \multirow{2}{*}{\multicolumn{4}{|c|}{$\begin{array}{c}\text { Odds Ratio } \\
\text { M-H, Fixed, } 95 \% \mathrm{Cl}\end{array}$}} \\
\hline & Events & Total & Events & Total & Weight & M-H, Fixed, 95\% Cl & & & & \\
\hline PRECOMBAT & 14 & 89 & 10 & 91 & $27.4 \%$ & $1.51[0.63,3.61]$ & & & & \\
\hline SYNTAX LM Subgroup & 62 & 135 & 43 & 149 & $72.6 \%$ & $2.09[1.28,3.42]$ & & & - & \\
\hline Total $(95 \% \mathrm{Cl})$ & & 224 & & 240 & $100.0 \%$ & $1.93[1.26,2.96]$ & & & & \\
\hline Total events & 76 & & 53 & & & & & & & \\
\hline $\begin{array}{l}\text { Heterogeneity: } \mathrm{Chi}^{2}=0 \text {. } \\
\text { Test for overall effect: } Z\end{array}$ & $\begin{array}{l}1, d f=1 \\
3.03(P=\end{array}$ & $\begin{array}{l}P=0.5 \\
0.002)\end{array}$ & $2) ; I^{2}=0^{0}$ & & & & 0.01 & $\begin{array}{c}0.1 \\
\text { Favours stenting }\end{array}$ & $1 \frac{10}{\text { Favours CABG }}$ & 100 \\
\hline
\end{tabular}

Subgroup: low-to-intermediate SYNTAX score *

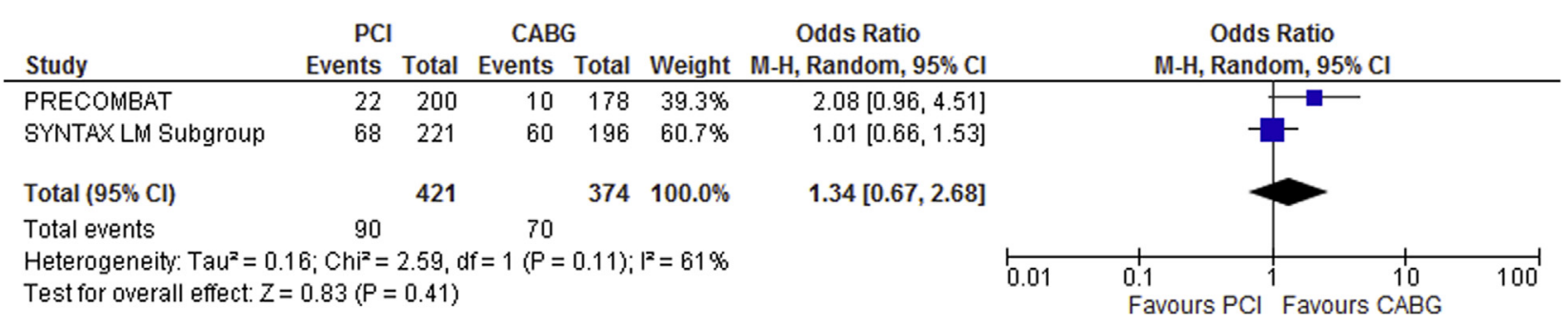

FIGURE 1. Forest plot for major adverse cardiac and cerebrovascular events in percutaneous coronary intervention (PCI) versus coronary artery bypass grafting $(C A B G)$ groups. Asterisk indicates data available from SYNTAX ${ }^{2}$ and PRECOMBAT ${ }^{4}$ trials only. $M-H$, Mantel-Haenszel; $C I$, confidence interval; $L M$, left main coronary artery disease. 
particularly evident among patients with complex lesions. Efforts should be undertaken to reduce the incidence of stroke, however, which remains higher in patients undergoing CABG. Aortic "no touch" off-pump CABG has been recently proposed as a means of minimizing the risk of perioperative stroke. The rate of off-pump surgery varied among the trials included, ranging from $1.8 \%{ }^{5}$ to $63.8 \%{ }^{4}$ A trend toward an increased rate of stroke was found among patients undergoing CABG regardless of the rate of off-pump surgery. No data were available on manipulation of the ascending aorta or the use of epiaortic scanning, however, so whether off-pump surgery would truly be beneficial cannot be evaluated, and further studies are needed.

Despite these limitations, this meta-analysis demonstrates a significant reduction in repeated revascularization with $\mathrm{CABG}$, which outweighs its detrimental increase in stroke rate. Only first-generation DESs were used in all the included RCTs, however, limiting our ability to draw conclusions for second-generation devices.

\section{References}

1. Athappan G, Patvardhan E, Tuzcu ME, Ellis S, Whitlow P, Kapadia SR. Left main coronary artery stenosis: a meta-analysis of drug-eluting stents versus coronary artery bypass grafting. JACC Cardiovasc Interv. 2013;6:1219-30.

2. Morice MC, Serruys PW, Kappetein AP, Feldman TE, Ståhle E, Colombo A, et al. Five-year outcomes in patients with left main disease treated with either percutaneous coronary intervention or coronary artery bypass grafting in the SYNTAX Trial. Circulation. 2014;129:2388-94.

3. Boudriot E, Thiele H, Walther T, Liebetrau C, Boeckstegers P, Pohl T, et al. Randomized comparison of percutaneous coronary intervention with sirolimuseluting stents versus coronary artery bypass grafting in unprotected left main stem stenosis. J Am Coll Cardiol. 2011;57:538-45.

4. Park SJ, Kim YH, Park DW, Yun SC, Ahn JM, Song HG, et al. Randomized trial of stents versus bypass surgery for left main coronary artery disease. $N$ Engl J Med. 2011;364:1718-27.

5. Buszman PE, Kiesz SR, Bochenek A, Peszek-Przybyla E, Szkrobka I, Debinski M, et al. Acute and late outcomes of unprotected left main stenting in comparison with surgical revascularization. J Am Coll Cardiol. 2008;51: $538-45$.

\title{
Single-center experience with a minimally invasive apicoaxillary external ventricular assist device
}

\author{
Elissa Landes, MD, Yoshifumi Naka, MD, PhD, Koji Takeda, MD, PhD, and Hiroo Takayama, MD, PhD, \\ New York, NY
}

Mechanical circulatory support (MCS) devices have become more popular in the treatment of cardiogenic shock (CS). Options for emergency support include venoarterial extracorporeal membrane oxygenation, percutaneous ventricular assist devices (VADs), and surgical VADs. Among MCS devices, surgical VADs have the advantage of providing sufficient circulatory support ${ }^{1}$; however, the standard technique requires implantation through a median sternotomy. ${ }^{2}$

Previously, we described a unique configuration of the CentriMag (Thoratec Corporation, Pleasanton, Calif) left VAD (LVAD) that allowed rapid off-pump placement without performing a sternotomy. ${ }^{3}$ Here we present a series

\footnotetext{
From the Department of Surgery, Columbia University Medical Center, New York, NY.

Disclosures: Yoshifumi Naka reports consulting fees from Thoratec. All other authors have nothing to disclose with regard to commercial support.

Received for publication April 18, 2014; revisions received June 29, 2014; accepted for publication July 14, 2014; available ahead of print Aug 28, 2014.

Address for reprints: Hiroo Takayama, MD, PhD, 177 Fort Washington Ave, New York, NY 10032 (E-mail: ht2225@cumc.columbia.edu).

J Thorac Cardiovasc Surg 2014;148:2432-4

$0022-5223 / \$ 36.00$

Copyright (C) 2014 by The American Association for Thoracic Surgery

http://dx.doi.org/10.1016/j.jtcvs.2014.07.086
}

of cases of patients who received this external apicoaxillary LVAD (AA-LVAD) as a bridge to decision.

\section{MATERIALS AND METHODS}

Our institutional review board approved this study. Between January 2007 and December 2013, a series of 198 patients underwent CentriMag VAD insertion for CS at our institution. The cases of 7 patients who received AA-LVADs were reviewed.

\section{Indications}

Indications for AA-LVAD placement include patients in CS who require VAD support but do not meet criteria for durable MCS device implantation at the time of evaluation. Our default strategy for device therapy in CS is to insert a short-term biventricular VAD, so this technique is reserved for those who can succeed with isolated LVAD support. Patients with CS who have peripheral vascular disease that precludes the use of a percutaneous MCS may also be considered for this support. Patients are excluded if there are mechanical obstacles to cannulation of their axillary artery or left ventricular apex.

\section{Technique}

The details of AA-LVAD implantation are described elsewhere. Briefly, after intubation, the axillary artery (right or left) is exposed through a small infraclavicular incision, and the left ventricular apex is exposed through a left anterior thoracotomy. Heparin of 5 to 10,000 units is given. An 8-mm Dacron polyester fabric graft is sewn end to side to the axillary artery, and the arterial cannula (24F EOPA; Medtronic, Inc, 